\title{
The Curious Silence of the Dog and Paul of Tarsus: Revisiting The Argument from Silence
}

\author{
Mike DUnCAN
}

University of Houston Downtown

One Main Street

Houston, Texas 77002

duncanm@uhd.edu

\begin{abstract}
In this essay I propose an interpretative and explanatory structure for the so-called argumentum ex silento, or argument from silence (henceforth referred to as the AFS). To this end, I explore two examples, namely, Sherlock Holmes's oftquoted notice of the "curious incident of the dog in the night-time" from Arthur Conan Doyle's short story "Silver Blaze," and the historical question of Paul of Tarsus's silence on biographical details of the historical Jesus. Through these cases, I conclude that the AFS serves as a dialogical topos best evaluated and understood through the perceived authority of the arguer and the willingness of the audience to accept that authority, due to the "curious" nature of the negative evidence that the argument employs.
\end{abstract}

Résumé: Dans cet essai, je propose une structure interprétative et explicative pour le soi-disant argumentum ex silento, ou un argument qui fait appel au silence (ci-après dénommé 1 'AFS). À cette fin, j'explore deux exemples, à savoir, une remarque souvent citée de Sherlock Holmes, "l'incident curieux du chien [silencieux] dans la nuit" tiré du conte "Silver Blaze" de Arthur Conan Doyle et la question historique du silence de Paul de Tarse sur les détails biographiques du Jésus historique. Grâce à ces cas, je conclus que l'AFS sert d'un topos dialogique mieux évalué et compris à travers l'autorité perçue de la personne qui avance l'argument et à travers la volonté de l'auditoire d'accepter cette autorité, en raison de la "curieuse" nature de la preuve négative que l'argument emploie.

Keywords: acceptability, argument from silence, authority, dialectic, expertise, fallacy, rhetoric.

\section{Past and current thought}

Scholarly examinations of the Argument From Silence (AFS) are extremely rare; when existent, it is typically treated as a fallacy. ${ }^{1}$ However, of the two indispensable theoretical texts on

\footnotetext{
1 Lange, writing in 1966, mines a smattering of texts on historiography, ranging from 20-80 years old at his writing (288); his piece, as well as the (C) Mike Duncan. Informal Logic, Vol. 32, No. 1, (2012), pp. 83-97.
} 
fallacies in the last 2500 years, Aristotle's Sophistical Refutations and Hamblin's Fallacies, neither explicitly mentions an argument from silence, ${ }^{2}$ and nor is it mentioned in the developing pragma-dialectical standards (van Eemeren et al).

The practical dimensions of the AFS vary, save the constant that a lack of evidence is presented as evidence that something is possible, what Stephens calls "absent evidence reasoning" (56). Sometimes, the claim of possibility is extended to "probable" or "highly probable," the latter examples tending to attract a charge of logical impossibility. Quite often, though, even the more modest claim of "possible" receives the same logic critique.

Behind this critique is the assumption that considering apparent lack of evidence as evidence of actual lack of evidence is to go too far, which in turn raises the question of how any lack of evidence can ever be established as meaningful. Advice considering AFS use is universally tinged with caution. This particular critique is widespread enough that it is difficult to locate a positive use of the phrase "argument from silence" in the literature of any field - an observation that, itself, constitutes an AFS.

John Lange's exploration of the AFS in 1966 notes its worth as a historical argument and its critiqued status in research methodologies. Lange rejects an insistence that the AFS must be conclusive in all cases (290), realizing that this would throw out all kinds of historical arguments that are commonly perceived as reasonable. Instead, he cannibalizes a relatively relaxed set of preconditions from historiographical texts (which presuppose that the dating/existence of a historical event is under question):

1. There is a document, $D$, or a functional equivalent thereof, which is extant, in which the event, $E$, is not mentioned.

2. It was the intention of the author of $D$ to enumerate exhaustively all members of the class of events of which $E$ is supposed to be a member.

3. $E$ must be such that, if it had occurred, the author of $D$ could not have overlooked it (290-291).

brief discussion in Brickman's 1949 Guide to Research in Educational History (170-172) is very dependent on Gilbert Garraghan's 1946 A Guide to Historical Method.

${ }^{2}$ This is a pretty strong example of an AFS in action. If Aristotle and Hamblin did not mention the AFS - especially Hamblin - they very likely did not think it was a fallacy, or that it was worthy of discussion in context of fallacy. Both discuss the argument from ignorance, though, which has some similarities, as Walton discusses (374). 
Lange concludes that "specific instances" of the AFS must be evaluated individually; there are no good general dialectical rules to follow, save perhaps expertise with the evidence offered (290-291). Dismissing all instances is counterproductive, as AFS is never logically or rationally conclusive, only suggestive (301). Lange's singular study in important, but he does not provide an extended example of an AFS to show how it interacts with other competing arguments on the same question, or provide guidelines for assessing its strength relative to those other competing arguments. He does call for such guidelines, ideally cooperatively developed by a "historian and some probability logician," but does not offer any (301). He does provide several short AFS examples taken from methodological works (289), but he does not explore any of them.

Douglas Walton briefly discusses the AFS as a variant of argumentum ad ignorantiam or appeal to ignorance (371). He compares it to the standard of negative evidence in scientific research, which is typically devalued when compared to the power of positive evidence (372). Walton does not explore the AFS much further, but he seems to hold that like in other nonfallacious uses of argumentum ad ignorantium, that the AFS, at least when nonfallacious, is based on knowledge - albeit of a negative kind-rather than ignorance (373). For example, Walton outlines several instances of apparently nonfallaicous arguments from ignorance, including a lengthy textbook example where the FBI fails to find any evidence showing than a "Mr. $X$ " is a communist, and therefore concludes that $\mathrm{Mr}$. $\mathrm{X}$ is probably not a communist, As this instance "combines ignorance with knowledge," through the extensiveness of the FBI's search, the resulting argument is more persuasive (371). The special nature of this negative knowledge, however, is not explored further.

Most recently, Christopher Stephens has offered a Bayesian approach to absent evidence reasoning, suggesting that the epistemological motto "absence of evidence is not evidence of absence" does not hold true in cases where evidence has been actively searched for (such as the FBI example featured in Walton) as the results of such a search constitute evidence that shifts the probability of a question, given an informal logic framework (56). While Stephens clarifies to an extent the nature of the knowledge produced by observing silence in such arguments, and confirms the nonfallacious nature of the motto in such special cases, he does not examine the effect of the arguer(s) and or the audience(s) on the argument, both of which are crucial to evaluating its informal structure and strength.

Reviewing Lange, Walton, and Stephens suggests that more could be learned about the AFS by reviewing several AFS 
examples at length to determine, first, how negative knowledge operates differently than other kinds of offered evidence (in other words, what makes the AFS different from other arguments) and second, how the rhetorical relationship between arguer, audience, and context affects use and reception of the AFS. As such, I offer the following two case studies-both well-known, though one is fictional in nature, and the other historical by nature - as fodder for discussion.

\section{The curiously silent dog}

In Arthur Conan Doyle's short story "Silver Blaze," Sherlock Holmes is investigating a murder that involves a stolen horse, Silver Blaze, who has gone missing from a stable. Upon realizing that the stable's resident dog did not bark on the night of the crime-Holmes is not told this, but infers it through no one mentioning a bark ${ }^{3}$ - he further infers that the horse was stolen by someone the dog knew well. ${ }^{4}$ His reasoning might be broken down thusly:

The dog would have barked at any strangers in the stables on the night in question.

The dog did not bark on the night in question.

Therefore, the dog probably did not encounter a stranger on the night in question.

As such, Silver Blaze probably was not stolen by a stranger to the stables.

This example introduces the main limitation of the AFS. It can only ever establish probability, though the prima facie case produced by a strong AFS is often valuable. In this case, the dog's lack of alarm alerts Holmes to the possibility and probability that the horse was stolen by someone the dog knew.

It is critical to note that the following argument, while initially seeming very similar, is quite different:

The dog would have barked at all strangers in the stables on the night in question.

The dog barked on the night in question.

\footnotetext{
${ }^{3}$ In a way, this is a double-layered AFS; Holmes takes the absence of notification of a bark as the absence of a bark.

${ }^{4}$ Holmes's explanation of the significance of the dog's silence (Doyle 280) suggests that he made the inference well before his initial and well-quoted comment on it (Doyle 277).
} 
Therefore, the dog probably encountered a stranger that night.

As such, Silver Blaze probably was stolen by a stranger to the stables.

The difference lies in how a definite event (the barking) can be easily deemed evidence, while the lack of an event (the absence of barking) is more difficult to grasp intuitively as a premise. When Holmes calls the silence a "curious incident," Doyle plays with the notion of what an "incident" is; how can the absence of something be an event?

Cheryl Glenn has shown powerfully how silence itself can be a rhetorical act (2); the dog's silence on any given night, then, could be seen as testimony that there have been no strangers nearby, a tacit "all clear" signal, just as much as frequent barking means the opposite. That the guard is not human makes little difference; substitute a night watchman who shouts in alarm and the reasoning remains. In this sense, a silence or absence that violates previous notions of usual behavior can acquire a warrant and passes into the realm of "incident," and subsequently, evidence.

However, this transformation has special limitations, in that the perception of a gap in a pattern - in behavior, in the case of the dog - does not necessitate that the gap exists, or even that the gap, if existent, means anything or has a discernable cause, as Hume's example of the missing blue shade from his Enquiry suggests (12-13). Doyle plays with this special limitation in another Holmes story, where a man that Holmes has been following claims to have seen no one following him, and Holmes remarks dryly, "That is what you may expect to see when I follow you." The absence of evidence becomes evidence-but only through Holmes's interpretative act, and only if his judgment is accepted by the audience.

There is, perhaps, an even more curious and telling silence in "Silver Blaze," however, than that of the dog's: no one in the story criticizes the logic behind Holmes's snap inference. The premises are far from ironclad: the dog could have been asleep, or drugged (like the stableboy was), or placated with food, or even made its first exception for a friendly stranger. Likewise, the witnesses could have been mistaken about not hearing a bark through distraction or inattention - the dog may have actually barked quite a bit - or the witnesses could have been lying. Holmes' establishment of the reliability of the dog and the witnesses is simply assumed; there is no indication that he has ex-

\footnotetext{
${ }^{5}$ From "The Adventure of the Devil's Foot" (Doyle, 521).
} 
plored any of these possible alternate explanations. As such, his confidence in the evidence would be fallacious under the exploratory standard proposed by Stephens, as the silence in question is not sufficiently observed and confirmed.

However, this curious silence by potential, skilled critics-Dr. Watson and the police inspector-suggests that Holmes has so established himself as an expert in regard to the premises of the argument that they do not feel the need to question its relevance. Doyle dramatizes Holmes's statement by placing it at the very end of a scene (277), suggesting Holmes's audience was left speechless by either assuming Holmes as expert had made a connection they were unable to make themselves, or by realizing, perhaps dimly, the importance of his observation. In either case, Holmes assigns meaning to the dog's silence by the power of his authority as a well-respected consulting detective, who knows what kind of canine silences can constitute warranted evidence for claims - and Watson and the police accept this authority regardless of their own self-perceived levels of understanding.

It is also important to note the special function of this particular AFS in the larger scheme of Holmes's eventual solving of the story's mystery. Holmes's observation about the dog's silence functions a high-probability guess, a conductive stepping-stone that leads him to more solid argumentative ground where he can gather positive evidence that is more easily digestible. The dog's silence does not prove that Jonathan Straker, the actual thief, stole Silver Blaze, but making the assumption allows Holmes to construct theories about Straker's later death that would have been difficult to do so otherwise without conceiving of him as the horse thief. The AFS thus serves as an exploratory tool for Holmes, allowing him access to stronger evidence that eventually confirms rather than suggests Straker's theft of the horse.

"Silver Blaze," then, establishes two important points about the AFS. First, the highly probabilistic nature of the evidence shifts much of the burden of proof from the evidence itself to the strength of the arguer's ethos as an expert on such evidence. The comment of some random passerby on silence of the dog might or might not have led to further investigation (or, even, an inquiry into the reliability of the dog and the witness); a comment by Sherlock Holmes, however, focuses the attentions of the police and even the highly skeptical Colonel Ross. Second, the argument itself is a conductive stepping-stone on Holmes's way to a larger, more elaborative and conventionally supported argument about who stole the horse and who killed Straker. The silence of the dog is no longer questionable nega- 
tive evidence, but a necessary conductive link in Holmes's self-styled "chain of reasoning," where "one true inference invariably suggests others" (Doyle 279-280). His abductive reasoning style (Diderjean et al 15), which begins with an existing state of affairs and reasons backwards to find causes, would be impossible without such a tool.

\section{The curiously silent Paul of Tarsus}

I have offered the Holmes example for accessibility, but the AFS is also present in difficult historical questions. Doyle's Holmes, as observed before, enjoyed an absence of serious detractors in his opinion of the dog's silence, and he had considerable access to physical evidence. However, in the case of Paul of Tarsus's silence, there is no such uniformity of opinion, and no plethora of evidence.

Pauline scholarship in biblical studies has long wrestled with the question of how to explain why the known authentic letters of Paul of Tarsus present in the New Testament contain so little material concerning the life of a historical Jesus. Paul references no parables, no speeches, no birth narrative, no virgin birth, no John the Baptist, no miracle-working, no exorcisms, no trial, no scourging, and no accounts of most of the twelve apostles, especially Judas, among many other silences-some seemingly conspicuous, others not - that are too numerous to list individually here. The instances of relatively concrete knowledge of material that can also be found in the canonical gospels are scarce, besides the crucifixion and a few apparent teachings. ${ }^{6}$

Given these circumstances, it is possible to argue that Paul did not know of much of the material concerning Jesus's life in the canonical Christian gospels when writing his letters in the 50's and early 60's CE, because if he had known about this material, he would have mentioned more of it in his letters. The argument can be reduced to the following:

\footnotetext{
${ }^{6}$ Paul mentions Jesus has Davidic descent (Rom 1.1-3, Rom 9.3-5), that he was handed over during a possibly liturgical meal (1 Cor 11:23-27), and that he gave a directive to live from the gospel (1 Cor 9:14), as well as another directives on marriage and divorce (1 Cor 7:10-11). Furthermore, Paul offers a compact set of six accounts of post-resurrection appearances of Jesus, including his (Paul's) own revelation (1 Cor 15:3-5), and a few "nests" (Walter 56) of Jesus-like sayings (Rom 12:14-21, 1 Cor 4.11-13). The bulk of this material, save a few questionable parallels, is in two of the seven known authentic letters.
} 
Paul, writing earlier than the gospel authors, does not mention many key aspects of the life of Jesus in the gospels in his letters.

The gospel authors, writing later than Paul, mention a great deal of material about the life of Jesus in their works.

Therefore, Paul did not know much about the life of Jesus.

This argument is a non sequitor; Paul does not have to write about Jesus's life to know about it, and there is no necessary connection between the knowledge possessed by the gospel authors and Paul's knowledge.

Pointing out the logical error, though, does not address the core assumption behind this argument and behind all AFS usage in historiography; namely, the absence of many key details of Jesus's life in Paul's letters raises the possibility, however small, for Paul not knowing about much of Jesus's life, just as the dog's lack of barking in "Silver Blaze" caused Holmes to wonder if the dog knew the horse thief. In other words, if the two premises are accepted, then one must acknowledge that it is possible, however unlikely, that Paul does not know about much of the gospel material. This is not how the AFS is usually stated, though, so here is a sturdier version:

Paul, writing earlier than the gospel authors, does not mention many key aspects of the life of Jesus in the gospels in his letters.

The gospel authors, writing later than Paul, mention a great deal of material about the life

of Jesus in their works.

Therefore, other evidence notwithstanding, ${ }^{7}$ it is possible that Paul did not know much about the life of Jesus.

The carefully circumspect conclusion of this version is harder to challenge; it would require presenting evidence that Paul actually did know of Jesus's life outside of his letters, which would render the first premise true enough, but nothing more than a curiosity. A third premise, however, changes the argument significantly:

Paul wrote extensively on Jesus and would have mentioned major events in Jesus's life in his letters if he had known about them.

\footnotetext{
${ }^{7}$ I should note here that this form of the AFS is not some variant of modus tollens, as witnessed by "other evidence notwithstanding."
} 
Paul, writing earlier than the gospel authors, does not mention many key aspects of the life of Jesus in the gospels in his letters.

The gospel authors, writing later than Paul, mention a great deal of material about the life of Jesus in their works.

Therefore, other evidence notwithstanding, it is possible that Paul did not know much about the life of Jesus.

The new supporting premise depends on textual expertise rendering a judgment of probability, which lends the argument both strength and weakness; noting Paul's focus on Jesus helps the case, but it is difficult to qualify what "would have mentioned" amounts to. Rewording it as "probably would have mentioned" or even "more likely than not would have mentioned" does not help matters; the probability under question is unquantifiable and can only qualitatively judged, like the silence of the dog in "Silver Blaze," by a human expert who is familiar with the longterm reliability of similar evidence.

Stephens attempts to evaluate similar values with Bayesian analysis, but the Bayes theorem cannot tell us the level of increased probability the audience should take into consideration (62) as it cannot generate numerical values without numbers to input. As such, recalling the centrality of expertise, the AFS is not complete without the following rhetor-centric addition:

Paul wrote extensively on Jesus and would have mentioned major events in Jesus's life in his letters if he had known about them.

Paul, writing earlier than the gospel authors, does not mention many key aspects of the life of Jesus in the gospels in his letters.

The gospel authors, writing later than Paul, mention a great deal of material about the life of Jesus in their works.

Therefore, other evidence notwithstanding, in my professional opinion as an expert on early Christian history and Pauline discourse, it is probable that Paul did not know much about the life of Jesus.

The special evidential transformation that powers Holmes's professional inference about the horse theft also rests behind this version of the AFS; namely, some silences are "deafening" enough to an expert that they can establish probability, not just possibility, of a given state ("likely" rather than "unlikely") and that same probability then can become, potentially, acceptable to 
an audience. Holmes's argument, too, can be restated in a similar fashion:

The dog would have barked at all strangers in the stables on the night in question.

The dog did not bark on the night in question.

Therefore, other evidence notwithstanding, in my professional opinion as a counseling detective familiar with canine behaviors, the dog probably did not encounter a stranger that night.

As such, Silver Blaze was probably not stolen by a stranger to the stables.

\section{Acceptability, expertise, and mystery-solving}

Given Johnson and Blair's three standards for evaluating arguments-relevance, acceptability, and sufficiency (55), it is the acceptability standard where an AFS encounters difficulty. Relevance and sufficiency are handled by the judgment of the author/expert, but acceptability rests on that same ethos, especially if the audience lacks comparable expertise that would allow independent judgment of the evidence. Furthermore, even given comparable expertise, in the Pauline case, no level of persuasive ethos may be enough to sway opinion.

This ongoing requirement of an expert to champion an AFS suggests that the AFS is particularly dependent on authority; the evaluator must trust the arguer to have selected a silence that is relevant, meaningful, and warranted, and that trust must come from some judgment of the arguer's apparent expertise as much as the actual lack of evidence.

Fortunately for Holmes, the expertise required to show that a dog known to bark at strangers will almost certainly bark at a strange person in its demesnes is not terribly demanding to anyone familiar with dogs. However, there are many experts (and non-experts) on Pauline discourse that would not interpret Paul's silence on Jesus life as a strong suggestion he knew little about the subject. As such, the AFS must also deal with arguments that counter its claims.

A possible counterargument to an AFS concerning Paul's silence could be stated thusly:

Speaking as an expert on Pauline discourse, I hold that Paul probably knew all, most, or some of the material that we have in the canonical gospels. He did not mention this material much in his letters because he had no need or de- 
sire to do so, given he was strongly focused on a postearthly Jesus, and considered such material either A) trivial, well known, and not worthy of mention, B) inauthentic or corrupted compared to his personal revelation, $\mathrm{C}$ ) authentic, but not agreeable with his own teachings, which he wanted to stress, or D) some or all of the above.

Comparing this counterargument to the AFS stated earlier reveals some interesting structural details. First, a multitude of possible Pauls is postulated to counteract the single Paul of the AFS. While the AFS forms what Walter refers to as a "minimal hypothesis" on this question (53) - it does not need to assume more than what evidence is available at present - any counterargument must sort through a plethora of available options. It is possible to restate this counterargument using only one option (for example, option C), but that would forgo the usefulness of pointing out all of the other plausible options that the AFS has failed to consider. Their sheer numbers would seemingly overwhelm the AFS's lone claim and allow for Paul to exist in an ambiguous state that is in many ways more useful for Pauline scholarship, with its diversity of opinions. ${ }^{8}$

Second, the focus of the counterargument, like that of the matching AFS, concerns the meaning of Paul's silence. This depends on an understanding of who Paul was, and points toward the larger question of how the Pauline letters are to be interpreted at all. If, for example, Paul is a man who received a private revelatory vision of Jesus (Gal 1:11-16) that he holds higher than any message, myth, or narrative account coming out of the Jerusalem church, scholars must endeavor to read the letters (and the silence) in light of this ethical claim. If he was a pragmatist who balanced his revelation against various traditions or myths about Jesus that he encountered in his many travels about the Mediterranean (he was not the only roaming Christian missionary in the $1^{\text {st }}$ century $\mathrm{CE}$ ), scholars must interpret accordingly. If he was a controlling personality who would use any authoritative source of persuasion to keep the small

\footnotetext{
${ }^{8}$ This complicates the debate over the hypothetical Q sayings source, which is held to predate Paul's letters, and contains much Jesus material. Confidence in the existence of Q allows the question of Paul's knowledge of Jesus to be neatly sidestepped for many, for if Jesus sayings can be dated before Paul, then the need to defend Paul's knowledge of Jesus is considerably dampened, for a Jesus tradition is safely preserved elsewhere. If $\mathrm{Q}$ is ephemeral, however, then the question of Paul's knowledge of Jesus becomes far more pressing.
} 
churches he started under his prescriptions, likewise, scholars must read with this in mind.

Holmes's dog was not a human with a human's complexities, but the detective still had to judge its behavior-he assumed it was a consistent and reliable guard of the stables, and made assumptions based on this judgment. And, of course, Doyle allowed Holmes to solve his mystery through authorial fiat - we as readers know Holmes was correct in his judgment of the dog. But what about real-world AFS that cannot be confirmed and must exist simultaneously with counterarguments that also cannot be confirmed? It is not clear which Paul is the best version, or if any of the proposed versions are even close and even if we did know which Paul that we have in the letters, we still wouldn't know with confidence how much of the later gospel material he had, if any.

In spite of this limitation, however, the AFS in the Pauline scenario still can serve as a stepping-stone topos for proceeding with interpretations. Its "minimal hypothesis" helps reveal and organize the multitude of possibilities inherent in the question under consideration. For example, consider sub-claim (A) of the counterargument, that Paul could have considered the Jesus material that he did not mention to be trivial, well known, and not worthy of mention. Assuming Paul had visited, or would visit, each city and church that he addresses in the extent authentic letters, he would have had ample time to communicate and share traditions or sayings of Jesus with the congregations. As such, the letters are optional rather than necessary sites of Jesus material.

However, the AFS demands that this claim must be reconciled with the extent references in the letters. If Paul felt the congregation in Corinth knew the six post-resurrection appearances of Jesus well, why does he bother to mention them at all, much less list them in some detail as he does? Likewise, why mention a directive of Jesus at all when his usual fallback authority throughout the epistles is Hebrew scripture? Furthermore, on numerous occasions when knowledge of gospel materials would have greatly aided him in argument, he does not use such knowledge. ${ }^{9}$

As such, in order to develop reasonable answers to these AFS-inspired questions, a scholar can treat the AFS as a combination of a null hypothesis and stepping-stone. Unlike Holmes,

\footnotetext{
${ }^{9}$ For example, Paul does not invoke the memory of Judas or Peter's failure during the passion when discussing the incident at Antioch (Gal 2:11-14), and neither does he ever mention John the Baptist's endorsement or association with Jesus to buttress his near-constant claims of Jesus's importance.
} 
who proceeded in a linear fashion to the end of the mystery with the aid of his AFS, the Pauline AFS can promote the lateral and tangential motion that is suited to a hermeneutical question.

\section{Conclusions}

The argument from silence has several qualities that make it different from other arguments and complicate attempts to interpret its value and function.

First, the AFS has an inherently vague evidential threshold for success due its reliance on negative/absent evidence, which makes both using it and evaluating it something of a subjective art. This quality leads to a demanding, non-intuitive structure for its audience, compared to arguments that do not use negative/absent evidence.

Second, as the "Silver Blaze" example shows, it has an investigative quality that can be used as a pathway to further arguments that wield greater probability and acceptability. Also, as the Pauline case shows, when the AFS enters the lawless realm of rhetoric where questions with no immanent or demonstrable correct answers exist, it becomes a dialogical topos that cannot help but attract, and develop, counterarguments. Even if its offered possibility does not pan out, as Holmes's hunch did, an AFS can still serve an invaluable role in prompting investigation. This interrogative role, however, is dependent on a willingness by the audience to entertain assertions of unknown probability, which in turn is dependent on the audience's dialectical standards for such and their experience with the success of those standards.

For example, until Holmes came along, an inside job at the stables was not under serious consideration by authorities. Watson or the police inspector could have insisted that Holmes confirm the reliability of the dog and the witnesses before engaging in hypothetical musing; after all, an inside job was not a highprobability possibility to anyone else concerned with the case at that point, dog bark or no dog bark. By this methodological objection, however, the good doctor would have, at the very least, delayed the successful resolution of the case. Further investigation could have revealed, even, that the dog did bark, and have the unfortunate effect of sundering Holmes's confidence in his "chain of reasoning" before it led him to stronger evidence. ${ }^{10}$ Likewise, discouragement of the AFS on the Pauline question

${ }^{10}$ Doyle's Watson generally reserved his criticisms of Holmes's reasoning during a case, leaving the displays of incredulity to clients and the authorities. 
misses the opportunity to strengthen other explanations for Pauline silence. Accordingly, the most recent book collection fully concerned with the question of Pauline silence tends to returns to the AFS again and again in each essay, using it as a starting point regardless of the conclusions of each chapter (see Wedderburn, 1989).

Third, and perhaps most importantly, however, is the AFS's qualitative nature: its heavy dependence on the rhetor's expert judgment and the audience's evaluation of that judgment, which shifts the burden of proof from the stated evidence. The most popular metaphor for weighing AFS evidence, the perception of auditory volume-convincing silences are often described, counter-intuitively, as "deafening"-reinforces this, not only by lending the silence a metaphorical sound, but a "deafening" one, just in case no one else hears it. As such, interpretation of the strength or weakness of an AFS should proceed case-bycase, taking the acceptability issue of the relationship between the rhetor's apparent expertise and the audience's receptiveness into special account. Without such dialectical controls, it is easier to reject an AFS out of hand for using negative evidence, when closer consideration would have been more profitable for all parties.

\section{References}

Aristotle. (1955). On Sophistical Refutations, On Coming-to-be and Passing Away. On the Cosmos. Cambridge: Loeb.

Brickman, E. (2007). Guide to Research in Educational History (Reprint of Guide to Research in Educational History, New York University Bookstore, New York, 1949). Brickman Press.

Diderjean, A. and F. Gibet. (2008). "Sherlock Holmes-An Expert's View of Expertise." British Journal of Psychology, 99(1): 109-125.

Doyle, A.C. (1967). "Silver Blaze.” In W.S. Baring-Gould (Ed.), The Annotated Sherlock Holmes, Vol II, pp. 261-281. New York: Clarkson N. Potter.

Doyle, A.C. (1967). "The Adventure of the Devil's Foot." In W.S. Baring-Gould (Ed.), The Annotated Sherlock Holmes, Vol II, pp. 508-526. New York: Clarkson N. Potter.

Eemeren, F.H. van, B. Garssen and B. Meuffels. (2009). Fallacies and Judgments of Reasonableness: Empirical Research Concerning the Pragma-Dialectical Discussion Rules. New York: Springer. 
Garraghan, G.J., S.J. (1946). A Guide to Historical Method.

J. Delanglez, S.J. (Ed.). New York: Fordham University Press.

Glenn, Cheryl. (2004). Unspoken: A Rhetoric of Silence. Carbondale, IL: Southern Illinois University Press.

Hamblin, C.L. (2004). Fallacies. Newport News: Vale Press. (Reprint of 1970 edition.)

Hume, D. (1993). An Enquiry Concerning Human Understanding. $2^{\text {nd }}$ ed. Eric Steinberg (Ed.). Indianapolis: Hackett.

Johnson, R.H. and J.A. Blair. (2006). Logical Self-Defense. New York: IDEA.

Lange, J. (1966). “The Argument From Silence." History and Theory, 5(3): 288-301.

Stephens, C. (2011). "A Bayesian Approach to Absent Evidence Reasoning." Informal Logic, 31(1): 56-65.

Walter, N. (1989). "Paul and the Early Christian JesusTradition." In A.J.M. Wedderburn (Ed.), Paul and Jesus: Collected Essays, pp. 51-80. Worcester: Sheffield Academic Press.

Walton, D. (1999). "The Appeal to Ignorance, or Argumentum Ad Ignorantiam." Argumentation 13: 367-377.

Wedderburn, A.J.M. (Ed.). (1989). Paul and Jesus: Collected Essays. Worcester: Sheffield Academic Press. 